Discussion Paper No. 01-49

\title{
Climate Politics From Kyoto to Bonn: From Little to Nothing?!?
}

\author{
Christoph Böhringer
}

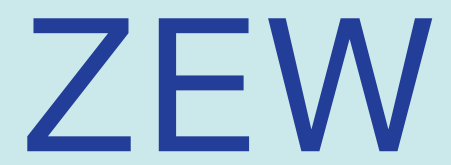

Zentrum für Europäische Wirtschaftsforschung GmbH

Centre for European Economic Research 



\section{Nontechnical Summary}

In this paper we assess how the U.S. withdrawal and the amendments of the Bonn conference will change the economic and environmental impacts of the Kyoto Protocol in its original form. Based on simulations with a large-scale computable general equilibrium model of global trade and energy use, we show that U.S. withdrawal from the Protocol implies a dramatic reduction in environmental effectiveness. If emission trading among remaining Annex B countries becomes more or less unrestricted, which seems to be rather likely after the Bonn outcome, the reduction of global carbon emissions as compared to $B A U$ will fall to zero. The reason is that supply of surplus emission rights from Russia, Ukraine, and Eastern Europe is large relative to the demand from OECD countries other than the U.S., driving down the permit price to zero. If non-U.S. OECD countries would opt for strictly domestic action in order to prevent hot air, the global emission cutback only amounts to roughly a third of the value that could be achieved for U.S. compliance while remaining OECD countries would suffer more or less the same non-negligible adjustment costs. Such a policy appears rather unacceptable to citizens in non-U.S. OECD countries - not only with regard to overall cost-effectiveness but also with respect to fairness considerations. Monopolistic permit supply by Russia, Ukraine and Eastern Europe may suppress a larger share of hot air and halve compliance costs of abating OECD countries as compared to strictly domestic action. However, environmental effectiveness falls too, with a global emission reduction around $1 \%$ for the revised Kyoto targets. Hopes remain that the U.S. might rejoin the Protocol under the new conditions of Bonn. Compliance costs to the U.S. economy seem rather moderate, which could enhance the domestic U.S. political pressure in favor of coordinated international abatement. 


\title{
Climate Politics From Kyoto to Bonn:
}

\section{From Little to Nothing ?!?}

\author{
Christoph Böhringer*
}

\begin{abstract}
We investigate how the U.S. withdrawal and the amendments of the Bonn climate policy conference in 2001 will change the economic and environmental impacts of the Kyoto Protocol in its original form. Based on simulations with a large-scale computable general equilibrium model, we find that U.S. withdrawal together with the new provisions of Bonn are likely to reduce environmental effectiveness to zero. U.S. compliance under the new Bonn amendments would accommodate a substantial cut in global emissions at small compliance costs for OECD countries rising some hopes that the U.S. might rejoin the Kyoto Protocol during the next years.
\end{abstract}

Key words: climate policy, emission trading, computable general equilibrium

JEL classification: D58, Q43, Q58

We would like to thank Sergey Paltsev and Thomas F. Rutherford (University of Colorado), Till Requate (University of Heidelberg), and Peter Zapfel (European Commission) for helpful comments. Financial support from the European Commission under the project Climate Change Policy and Global Trade (CCGT) and Greenhouse Gases Emission Control Strategies (GECS) is gratefully acknowledged. Regarding any remaining inadequacies, the usual caveat applies.

* Head of Department, Environmental and Resource Economics, Centre for European Economic Research (ZEW), P.O. Box 103443, D-68034 Mannheim, Germany. E-mail: boehringer@zew.de 


\section{Introduction}

The Kyoto Protocol, which was negotiated in 1997, requires industrialized countries to limit their emissions of greenhouse gases (GHG). In its original version, the Protocol was supposed to cut down the GHG emissions of the industrialized countries during the period 2008-2012 by an average of $5.2 \%$ below their 1990 levels. The agreement will not enter into force, however, until it has been ratified by at least 55 countries, and these ratifying countries must have contributed at least 55 percent of the industrialized world's $\mathrm{CO}_{2}$ emissions (the most important GHG) in 1990.

In March 2001, the U.S., under President Bush, declared its withdrawal from the Protocol reasoning that the costs to the U.S. economy would be too high and exemption of developing countries from binding emission targets would not be acceptable.

The U.S. withdrawal triggered a discussion among the remaining industrialized countries about whether or not to implement the Protocol in the absence of the U.S. The EU declared itself leader in a strategy of ratification without the U.S., but - in addition to EU approval - entering into force of the Protocol requires ratification by Japan, the Former Soviet Union (Russia and Ukraine) as well as Eastern Europe to get the necessary quorum. Russia, Ukraine and Eastern Europe were assumed to ratify, since they expect larger revenues from selling surplus emission rights. ${ }^{2}$ Japan confirmed its interest to keep alive the treaty bearing the name of its imperial city. However, it also stressed that the Protocol would make sense only if the U.S. - as the world's biggest polluter - would carry out the treaty.

In this context, delegates from 180 countries met in Bonn during July 2001, most of them determined to rescue the Kyoto global warming treaty from collapsing after a decade of negotiations. The negotiating parties agreed on a compromise paper which demanded numerous concessions, especially by the EU. Australia, Canada, New Zealand, Japan, and Russia were allowed a substantial credit for carbon dioxide sinks, namely forests and agricultural soils that store the greenhouse gas. The latter is supposed to considerably water down the provisions of the Protocol as originally agreed in 1997. Moreover, the restrictive position held by the EU with respect to the permissible scope of emissions trading between

\footnotetext{
${ }^{1}$ In 1997, the U.S. Senate unanimously passed the Byrd-Hagel resolution, which makes "meaningful" participation of developing countries a conditio sine qua non for ratification. Given that U.S. ratification requires a 2/3 majority in the Senate, the prospects for ratification have been rather small over the years, irrespective of the latest move under the Bush administration.

${ }^{2}$ Under the Kyoto Protocol, Eastern Europe, Ukraine and, particularly, Russia received much higher emission entitlements than they are expected to emit under business-as-usual between 2008-2012 (see e.g. Paltsev 2000). They will sell their excessive emission rights if industrialized countries can trade emission rights among each other to minimize overall costs of abatement.
} 
industrialized countries is no longer held up. The latest version of the Kyoto Protocol does not foresee any concrete caps on the share of emissions reductions a country can meet through the purchase of permits from other industrialized countries, nor does it envision a cap on the amount of permits it can sell. ${ }^{3}$ In fact, this means that Russia, Ukraine and Eastern Europe will be able to sell all their surplus emission permits - usually referred to as hot air - which may significantly increase the effective emissions under the Kyoto Protocol as compared to strictly domestic action. ${ }^{4}$

There is meanwhile an extensive literature providing quantitative evidence on the economic effects of the Kyoto Protocol (see Weyant 1999 or UNEP 2001 for summary reports). However, this literature does not incorporate the most recent substantial changes in international climate politics, i.e. the U.S. withdrawal from the Kyoto Protocol and the provisions of the Bonn conference on sink credits.

The objective of this paper is to assess how the U.S. withdrawal and the amendments of the Bonn conference will change the economic and environmental impacts of the Kyoto Protocol in its original form. Based on simulations with a large-scale computable general equilibrium model of global trade and energy use, our key findings can be summarized as follows:

(i) Non-compliance of the U.S. reduces environmental effectiveness of the Kyoto Protocol practically to zero if there are no restrictions to emission sales from Russia, Ukraine and Eastern Europe. In this case, the demand for emission permits of remaining OECD countries is sufficiently small to drive down the price of permits almost to zero given the large supply of surplus emission rights from Russia, Ukraine and Eastern Europe. In short, Kyoto more or less boils down to business-as-usual without binding emission constraint.

(ii) Restrictions to emissions trading in order to avoid hot air makes global abatement for non-U.S. OECD countries rather costly. For strictly domestic abatement, the reduction in global emissions only amounts to a third of the value that would be achieved for

\footnotetext{
${ }^{3}$ It has been agreed that the use of emissions trading "shall be supplemental to domestic action and domestic action shall thus constitute a significant element of the effort made by each Party .... to meet its quantified emission limitation and reduction commitments ..." (UNFCCC 2001). The undefined term "significant" gives sufficient leeway for comprehensive trading.

${ }^{4}$ The effects of restrictions on permit imports and exports have been examined more recently in Bernstein et al. (1999), Bollen et al. (1999), Criqui et al. (1999), Böhringer (2000), and Ellerman and Wing (2000).
} 
U.S. compliance, whereas total costs for abating OECD countries would remain roughly the same.

(iii) Monopolistic permit supply by Russia, Ukraine and Eastern Europe may suppress a larger share of hot air and halve compliance costs of abating OECD countries as compared to strictly domestic action. However, environmental effectiveness falls too, leading to a global emission reduction of only $1 \%$ as compared to business-as-usual.

(iv) Under U.S. compliance, adoption of sink credits together with unrestricted emissions trading, accommodates very small compliance costs for OECD while global emissions would still fall by roughly $4 \%$. The consumption loss to U.S. seems small enough around $0.25 \%$ of the business-as-usual consumption level - to justify hopes that the U.S. might rejoin the Kyoto Protocol during the next years.

Sensitivity analysis with respect to changes in key model assumptions (such as fossil fuel price responsiveness, ease of substitution among traded non-energy goods, or baseline projections for economic and emission growth) confirm the robustness of the above results. ${ }^{5}$ Nevertheless, several caveats apply which may be addressed in future research once the relevant information and data is available: First, our analysis does not cover a further commitment period after 2012 that might influence behavior in the first commitment (e.g. through banking of emission permits). Second, we assume for the case of U.S. withdrawal that the U.S. will not undertake any domestic policies to cut GHG emissions. Third, no other greenhouse gas besides $\mathrm{CO}_{2}$ is incorporated in our analysis.

The remainder of the paper is organized as follows. Section 2 provides a brief nontechnical summary of the underlying modeling framework. Section 3 entails a description of the policy scenarios. Section 4 presents the interpretation of simulation results. Section 5 concludes.

\section{Analytical Framework and Baseline Calibration}

Carbon abatement policies not only cause direct adjustments on fossil fuel markets, but they produce indirect spillovers to other markets that, in turn, feed back to the economy. General

\footnotetext{
${ }^{5}$ For the sake of brevity, we do not present the sensitivity analysis in this paper. The programs and data to reproduce the results of the core simulations as well as the sensitivity analysis are readily available from the authors on request.
} 
equilibrium provides a consistent framework for studying price-dependent interactions between the energy system and the rest of the economy. The simultaneous explanation of the origin and the spending of income of the economic agents makes it possible to address both economy-wide efficiency as well as equity implications of abatement policy interference. Therefore, computable general equilibrium (CGE) models have become a standard tool for the analysis of the economy-wide impacts of greenhouse gas abatement policies on resource allocation and the associated implications for incomes of economic agents (Bergmann 1990, Grubb et al. 1993, Weyant 1999).

For our analysis, we use a static 7-sector, 12-region computable general equilibrium (CGE) model of the world economy. The choice of sectors captures key dimensions in the analysis of carbon abatement such as differences in carbon intensities and the scope for substitutability across energy goods and carbon-intensive non-energy goods. The regional aggregation covers the Annex-B parties as well as major non-Annex-B regions that are central to the greenhouse gas issue. Table 1 summarizes the sectors and regions incorporated in our model. For the sake of brevity, we abstain here from the exposition of the functional forms as well as central model assumptions which are standard within the CGE analysis of multilateral carbon abatement policies. A detailed algebraic model description is provided in Appendix A.

Table 1: Overview of sectors and regions ${ }^{\mathrm{a}}$

\begin{tabular}{llll}
\hline Sectors & & Countries & \\
\hline Energy & & Annex $B$ & \\
COL & Coal & USA & United States \\
CRU & Crude oil & EUR & OECD Europe (incl. EFTA) \\
GAS & Natural gas & JPN & Japan \\
OIL & Refined oil products & CAN & Canada \\
ELE & Electricity & AUN & Australia, New Zealand \\
Non-Energy & & CEA & Central and Eastern Europe \\
EIS & Energy-intensive sectors & FSU & Former Soviet Union \\
\cline { 2 - 3 } ROI & Rest of industry & Non-Annex $B$ & \\
& & CHN & China \\
& & IND & India \\
& & ASI & Asia \\
& & MPC & Mexico and OPEC \\
& & ROW & Rest of world \\
\hline
\end{tabular}

\footnotetext{
${ }^{a}$ Aggregation based on the GTAP-EG dataset (see Appendix B).
} 
As is customary in applied general equilibrium analysis, the model is based on economic transactions in a particular benchmark year. Benchmark data determine parameters of the (nested CES) functional forms from a given set of benchmark quantities, prices, and elasticities (see Table A.1 for a summary of values of key elasticities). As to benchmark quantities and prices, we employ the GTAP 4 database (McDougall 1997) supplemented by OECD/IEA energy statistics (IEA 1996) for the year 1995 as described in Rutherford and Paltsev (2000).

The magnitude and distribution of abatement costs associated with the implementation of the Kyoto emission constraints crucially depend on the business-as-usual (BAU) projections for GDP, fuel prices, energy efficiency improvements, etc. (see e.g. Böhringer et al. (2000)). In our comparative-static framework, we infer the $B A U$ economic structure of the model's regions for the year 2010 using most recent projections on the economic development and future fossil fuel production. ${ }^{6}$ The forward calibration of the 1995 economies to 2010 incorporates exogenous information by the U.S. Department of Energy (DOE 1998) for GDP growth, energy demand and future energy prices. The fossil fuel production functions are finally calibrated to be consistent with exogenous estimates for supply elasticities.

\section{Policy Scenarios}

The set of scenarios reflects alternative options for implementing the Kyoto Protocol along three important dimensions of climate change policy, which are laid out in the following.

\section{A. Reduction Requirements}

The Kyoto Protocol fixes GHG emission limits for industrialized countries as listed in Annex $\mathrm{B}$ of the Protocol. In our simulations we consider two different schemes of emission reduction targets:

$O L D \quad$ Option $O L D$ considers a reduction target of $5.2 \%$ on average for industrialized countries which the Kyoto Protocol originally aspired to.

NEW Option NEW accounts for the compromise as agreed on in Bonn where significant credits for carbon dioxide sinks where allowed. Countries can offset some of the $\mathrm{CO}_{2}$ stored in their forests and farmlands to meet their emission limits.

\footnotetext{
${ }^{6}$ Simulation results for emission abatement scenarios are then measured with respect to the $B A U$ situation in 2010 (see section 4).
} 
Table 2 lists the original reduction targets $(O L D)$ as well as the revised targets $(N E W)$ for Annex-B countries. The revised targets are based on estimates for sink credits by the European Commission as listed in Appendix C. In our simulations, we apply the alternative reduction targets to carbon dioxide only which is the most important GHG among industrialized countries.

Table 2: Original Kyoto reduction targets $(O L D)$ and Bonn updates with sink credits $(N E W)$

\begin{tabular}{lcc}
\hline & $\begin{array}{c}\text { OLD Commitments }^{\mathrm{a}} \\
\text { (\% of 1990 base year GHG emissions) }\end{array}$ & $\begin{array}{c}\text { NEW Commitments }^{\mathrm{b}} \\
\text { (\% of 1990 base year GHG emissions) }\end{array}$ \\
\hline USA & 93.0 & 96.8 \\
EUR & 92.2 & 94.8 \\
JPN & 94.0 & 99.2 \\
CAN & 94.0 & 107.9 \\
AUN & 106.8 & 110.2 \\
CEA & 92.9 & 96.1 \\
FSU & 100.0 & 104.9 \\
\hline
\end{tabular}

${ }^{a}$ UNFCCC (1997)

${ }^{\mathrm{b}}$ Estimates by the EU commission on the basis of UNFCCC (2001)

\section{B. Scope of Emissions Trading}

The Bonn compromise does not set clear limits on the magnitude of international emissions trading that the industrialized countries could engage in to achieve their targets. The scope of permissible emissions trading has been a major point of disagreement between the U.S. and the EU. The EU wanted nations to make at least half of their emissions cuts within their own borders, whereas the U.S. wanted no limit on the purchase of emission rights from other countries.

In our simulations, we capture extreme points on the extent to which countries can meet their specific emission reduction commitments by abatement abroad (so-called whereflexibility). Unrestricted where-flexibility among Annex-B countries should be considered the relevant policy option emerging from the Bonn compromise: ${ }^{7}$

NTR Annex-B countries are restricted to domestic action for meeting their emission reduction commitments.

\footnotetext{
${ }^{7}$ At the end of section 4, we investigate how restrictions of FSU and CEA on the magnitude of their permit sales will affect results.
} 

equalization of marginal abatement costs but also allows countries to sell off abundant emission rights (hot air) that they would not have required in the NTR case.

\section{Participation of the U.S.}

In March 2001, the new U.S. administration under President G. W. Bush declared with respect to the Kyoto Protocol that "we have no interest in implementing this treaty." Since then, the EU has tried hard to persuade the U.S. to rejoin the Kyoto Process - so far, however, without success. Even the Bonn compromise could not appease the U.S., although it resolves several of the demands the U.S. had raised in the past - particularly concerning sink credits and international permit trading. It is nonetheless important for the international climate policy process to investigate how the economic and environmental impacts of the Kyoto Protocol change depending on the involvement of the U.S. We therefore take into account two options which deliver a useful angle of comparison:

USin Option "USin" assumes that the U.S. will keep with its Kyoto commitment.

USout Option "USout" reflects the current situation of U.S. climate policy in assuming that the USA will not be part of the Kyoto Protocol.

Table 3 summarizes the set of core scenarios that result from the combination of policy options as laid out above.

Table 3: Overview of scenarios

\begin{tabular}{l|cc|cc|cc}
\hline & \multicolumn{2}{|c|}{ Emission Reduction } & \multicolumn{2}{c}{ Emissions Trading } & \multicolumn{2}{c}{ U.S. Participation } \\
& OLD & NEW & NTR & TRD & USin \\
\hline USin_NTR_OLD & $\mathrm{X}$ & & $\mathrm{X}$ & & $\mathrm{X}$ \\
USout_NTR_OLD & $\mathrm{X}$ & $\mathrm{X}$ & $\mathrm{X}$ & $\mathrm{X}$ \\
USin_TRD_OLD & $\mathrm{X}$ & & $\mathrm{X}$ & $\mathrm{X}$ \\
USout_TRD_OLD & $\mathrm{X}$ & & $\mathrm{X}$ & $\mathrm{X}$ \\
USin_NTR_NEW & & $\mathrm{X}$ & $\mathrm{X}$ & $\mathrm{X}$ & \\
USout_NTR_NEW & & $\mathrm{X}$ & $\mathrm{X}$ & $\mathrm{X}$ & $\mathrm{X}$ \\
USin_TRD_NEW & & $\mathrm{X}$ & & $\mathrm{X}$ & \\
USout_TRD_NEW & & $\mathrm{X}$ & & $\mathrm{X}$ & \\
\hline
\end{tabular}




\section{Simulation Results}

The economic and environmental impacts induced by alternative scenarios for the implementation of the Kyoto Protocol are measured with respect to a $B A U$ reference point in 2010 without emission abatement policies. When we report results for the aggregate of Annex B or Non-Annex B (Label: NONAB) in the Tables below, we assume that the U.S. only forms part of Annex B or OECD if it sticks to its Kyoto commitments (US_in scenarios), otherwise the aggregate of Non-Annex B takes the U.S. into account. It should be noted that scenarios USin_NTR_OLD and USin_TRD_OLD reflect the policy settings that have been studied extensively in the literature on the economic impacts of the Kyoto Protocol. These simulations are repeated here to provide a consistent basis of comparison with the new scenarios capturing the implications of U.S. withdrawal and sink credits. All the results for USin_NTR_OLD and USin_TRD_OLD are in line with the quantitative estimates reported in previous studies (see Weyant 1999 and UNEP 2001).

\section{A. Compliance of the U.S. - No Emissions Trading}

We start discussion of simulation results for the scenarios USin_NTR_OLD and USin_NTR_NEW where the U.S. meets its Kyoto targets (in the $O L D$ or $N E W$ version) and reduction commitments are met exclusively by domestic action of Annex B countries.

Table 4 points out why the U.S. has withdrawn from the Protocol and why JPN, CAN as well as AUN have pushed hard for the relaxation of their Kyoto targets via the accounting of sinks and unlimited Annex-B emissions trading.

Emission constraints as originally mandated under the Kyoto Protocol induce nonnegligible adjustment costs to OECD countries. The reason is that emission targets, which are stated with respect to 1990, translate into much higher effective carbon reduction requirements with respect to business-as-usual emission levels during the Kyoto budget period between 2008-2012. Without "where"-flexibility, the effective emission constraints require substantial changes in the production and consumption patterns of OECD countries towards less carbonintensity which induces a loss of productivity and real income (consumption). ${ }^{8}$ Abatement in

\footnotetext{
${ }^{8}$ From a single country perspective, there is a straightforward monotonous correlation between the level of cutback, the induced marginal abatement cost and the associated infra-marginal welfare costs. However, as can be seen from Table 4, these relationships do not carry over for the comparison across countries, since differences in energy prices, energy intensities, substitution elasticities, etc. across countries also matter.
} 
OECD countries produces significant spillovers to non-abating regions through induced changes in international prices, i.e. the terms of trade.

Table 4: U.S. compliance and domestic abatement - impacts for $O L D$ and $N E W$ targets

\begin{tabular}{|c|c|c|c|c|c|c|c|c|}
\hline & \multicolumn{4}{|c|}{ USin_NTR_OLD } & \multicolumn{4}{|c|}{$U$ sin_NTR_NEW } \\
\hline & $\begin{array}{l}\text { Consumption } \\
\text { (in \% vs. BAU) }\end{array}$ & $\begin{array}{c}\mathrm{MAC}^{\mathrm{a}} \\
(\$ \mathrm{US} / \mathrm{t} \mathrm{C})\end{array}$ & $\begin{array}{c}\mathrm{CO}_{2} \text {-Cut } \\
\text { (in \% vs } B A U)\end{array}$ & $\begin{array}{c}\text { Leakage }^{\mathrm{b}} \\
\text { (in \%) }\end{array}$ & $\begin{array}{l}\text { Consumption } \\
\text { (in \% vs. } B A U \text { ) }\end{array}$ & $\begin{array}{c}\mathrm{MAC}^{\mathrm{a}} \\
(\$ \mathrm{US} / \mathrm{t} \mathrm{C})\end{array}$ & $\begin{array}{c}\mathrm{CO}_{2}-\mathrm{Cut} \\
\text { (in \% vs } B A U)\end{array}$ & $\begin{array}{c}\text { Leakage }^{\mathrm{b}} \\
\text { (in \%) }\end{array}$ \\
\hline USA & -0.67 & 170 & 28.2 & & -0.52 & 143 & 25.2 & \\
\hline EUR & -0.44 & 168 & 18.2 & & -0.34 & 139 & 15.9 & \\
\hline JPN & -0.88 & 394 & 28.3 & & -0.63 & 297 & 24.4 & \\
\hline CAN & -1.81 & 193 & 28.9 & & -1.03 & 108 & 18.3 & \\
\hline AUN & -1.05 & 85 & 16.8 & & -0.88 & 69 & 14.2 & \\
\hline CEA & 0.68 & 0 & -4.9 & & 0.57 & 0 & -4.3 & \\
\hline FSU & -0.66 & 0 & -4.8 & & -0.60 & 0 & -4.1 & \\
\hline $\mathrm{CHN}$ & -0.09 & & -1.4 & 2.5 & -0.07 & & -1.2 & 2.4 \\
\hline IND & 0.24 & & -1.5 & 0.6 & 0.21 & & -1.3 & 0.6 \\
\hline MPC & -0.73 & & -3.7 & 3 & -0.62 & & -3.2 & 2.9 \\
\hline ASI & 0.14 & & -3.8 & 2 & 0.12 & & -3.2 & 1.9 \\
\hline ROW & -0.07 & & -4.3 & 3.1 & -0.06 & & -3.7 & 3 \\
\hline TOTAL & -0.36 & & 9 & 11.1 & -0.28 & & 7.9 & 10.9 \\
\hline NONAB & -0.08 & & & & -0.07 & & & \\
\hline ANNEXB & -0.46 & & & & -0.34 & & & \\
\hline OECD & -0.47 & & & & -0.34 & & & \\
\hline
\end{tabular}

${ }^{a}$ MAC: marginal abatement costs

${ }^{\mathrm{b}}$ Ratio of emission change in non-abating region over aggregate emission reduction in abating regions

Most important are changes on international fuel markets for crude oil, gas and coal. The cutback in global demand for fossil fuels implies a significant drop of their prices providing economic gains to fossil fuel importers and losses to fossil fuel exporters. These fossil fuel market effects explain most of the welfare impacts for non-abating countries. The economic implications of international price changes on non-energy markets are more complex. Higher energy costs raise the prices of non-energy goods (in particular energyintensive goods) produced in abating countries. Countries that import these goods suffer from higher prices to the extent that they can not substitute away towards cheaper imports of nonabating countries. The ease of substitution not only determines the implicit burden shifting via

\footnotetext{
${ }^{9}$ See Böhringer and Rutherford (2001) for an elaborate discussion of terms-of-trade effects from carbon abatement.
} 
non-energy exports from abating countries but also the extent to which non-abating countries achieve a competitive advantage vis-à-vis abating exporters. The gain in market shares due to substitution effects may be partially offset by an opposite scale effect: Due to reduced economic activity and income, import demand by the group of abating countries (here: Annex B) declines, and this exerts a downward pressure on the export prices of non-abating countries.

Adoption of the less stringent emission targets as adopted in Bonn reduces welfare costs of the Annex B group by more than $25 \%$ - the adjustment costs to OECD countries, however, remain substantial.

With respect to environmental effectiveness, domestic abatement by Annex B countries implies a global reduction of carbon emission by $9 \%(O L D)$ or $7.9 \%(N E W)$ compared to $B A U$. Leakage, which is mainly caused by increased fossil fuel demand of nonabating countries and shifts in the pattern of energy-intensive trade, amounts to more than $10 \% .^{10}$

\section{B. Withdrawal of the U.S. - No Emissions Trading}

Next, we move to the economic and environmental implications of U.S. withdrawal for the NTR cases, which are reported in Table 5. At the single-region level, the induced consumption changes as compared to the case of U.S. compliance illustrates the importance of terms-oftrade effects. EUR and JPN are worse off because international fuel prices under U.S. withdrawal are not depressed as much and, therefore, terms-of-trade gains for fuel importers decrease. The latter effect becomes even more obvious for non-abating developing countries IDI and ASI. Fuel exporters such as CAN, FSU, MPC or ROW, on the other hand, do better. The key message of Table 5, however, is that U.S. withdrawal dramatically reduces costeffectiveness of global emission reduction. Total costs for remaining Annex B countries slightly increase while global emission reduction drops by a factor of 3 as compared to the scenario where the U.S. would not drop out. ${ }^{11}$

\footnotetext{
${ }^{10}$ A leakage rate of $10 \%$ implies that non-abating countries offset a tenth of the carbon reduction achieved in abating countries.

${ }^{11}$ Non-participation of the U.S. not only implies that the direct U.S. contribution to global emission reduction drops out, but also counterproductive leakage more than doubles as compared to the USincase. The U.S. now becomes the major source of leakage due to increased domestic fossil fuel demand induced by the drop of fuel consumption prices.
} 
Table 5: Impacts of U.S. withdrawal for the NTR case (OLD and NEW targets)

\begin{tabular}{|c|c|c|c|c|c|c|}
\hline & \multicolumn{6}{|c|}{ Emission Reduction Option: $O L D$} \\
\hline & \multicolumn{2}{|c|}{ Consumption (in \% vs. $B A U$ ) } & \multicolumn{2}{|c|}{$\mathrm{CO}_{2}$-Cut (in \% vs. $B A U$ ) } & \multicolumn{2}{|c|}{ Leakage $^{\mathrm{a}}$ (in \%) } \\
\hline & USin_NTR & USout_NTR & USin_NTR & USout_NTR & USin_NTR & USout_NTR \\
\hline USA & -0.67 & 0.02 & 28.2 & -2 & & 9.1 \\
\hline EUR & -0.44 & -0.53 & 18.2 & 18.2 & & \\
\hline JPN & -0.88 & -0.95 & 28.3 & 28.3 & & \\
\hline CAN & -1.81 & -1.09 & 28.9 & 28.9 & & \\
\hline AUN & -1.05 & -0.90 & 16.8 & 16.8 & & \\
\hline CEA & 0.68 & 0.35 & -4.9 & -3.7 & & \\
\hline FSU & -0.66 & -0.50 & -4.8 & -3.5 & & \\
\hline $\mathrm{CHN}$ & -0.09 & -0.09 & -1.4 & -0.9 & 2.5 & 3.7 \\
\hline IND & 0.24 & 0.09 & -1.5 & -0.8 & 0.6 & 0.7 \\
\hline MPC & -0.73 & -0.29 & -3.7 & -1.9 & 3 & 3.5 \\
\hline ASI & 0.14 & 0 & -3.8 & -2.3 & 2 & 2.8 \\
\hline ROW & -0.07 & -0.08 & -4.3 & -2.7 & 3.1 & 4.5 \\
\hline TOTAL & -0.36 & -0.25 & 9 & 3.1 & 11.1 & 24.2 \\
\hline NONAB & -0.08 & -0.02 & & & & \\
\hline ANNEXB & -0.46 & -0.48 & & & & \\
\hline \multirow[t]{4}{*}{ OECD } & -0.47 & -0.50 & & & & \\
\hline & \multicolumn{6}{|c|}{ Emission Reduction Option: $N E W$} \\
\hline & \multicolumn{2}{|c|}{ Consumption (in \% vs. $B A U$ ) } & \multicolumn{2}{|c|}{$\mathrm{CO}_{2}$-Cut (in \% vs. $B A U$ ) } & \multicolumn{2}{|c|}{ Leakage $^{1}$ (in \%) } \\
\hline & USin_NTR & USout_NTR & USin_NTR & USout_NTR & Usin_NTR & USout_NTR \\
\hline USA & -0.52 & 0.02 & 25.2 & -1.6 & & 8.8 \\
\hline EUR & -0.34 & -0.42 & 15.9 & 15.9 & & \\
\hline JPN & -0.63 & -0.70 & 24.4 & 24.4 & & \\
\hline CAN & -1.03 & -0.46 & 18.3 & 18.3 & & \\
\hline AUN & -0.88 & -0.74 & 14.2 & 14.2 & & \\
\hline CEA & 0.57 & 0.28 & -4.3 & -3.2 & & \\
\hline FSU & -0.60 & -0.45 & -4.1 & -3 & & \\
\hline CHN & -0.07 & -0.07 & -1.2 & -0.8 & 2.4 & 3.6 \\
\hline IND & 0.21 & 0.07 & -1.3 & -0.7 & 0.6 & 0.7 \\
\hline MPC & -0.62 & -0.23 & -3.2 & -1.5 & 2.9 & 3.4 \\
\hline ASI & 0.12 & 0 & -3.2 & -1.8 & 1.9 & 2.6 \\
\hline ROW & -0.06 & -0.06 & -3.7 & -2.3 & 3 & 4.5 \\
\hline TOTAL & -0.28 & -0.19 & 7.9 & 2.7 & 10.9 & 23.6 \\
\hline NONAB & -0.07 & -0.02 & & & & \\
\hline ANNEXB & -0.34 & -0.36 & & & & \\
\hline OECD & -0.34 & -0.37 & & & & \\
\hline
\end{tabular}

${ }^{a}$ Ratio of emission change in non-abating region over aggregate emission reduction in abating regions 
In other words: If the welfare costs for non-U.S. Annex B countries under USin_NTR correspond to their average willingness-to-pay, as would be ideally the case, U.S. withdrawal from the Kyoto Protocol would require a tripling of this willingness-to-pay.Given empirical evidence on the low willingness-to-pay for climate change even in industrialized countries (Böhringer and Vogt 2001), the dilemma from a political economy point of view becomes obvious. Besides, the USout_NTR-scenarios would also appear rather unfair to voters in abating non-U.S. OECD countries, since they have to bear substantial welfare costs while the U.S economy remains basically unaffected.

But not only acceptance in remaining OECD countries seems unrealistic. Independent of U.S. withdrawal, FSU wouldn't like any scenario without emissions trading because then it would face overall consumption losses due to negative terms-of-trade effects (in particular with respect to its gas and oil export revenues). In this context, it should be noted that the U.S. position has an important impact on the potential bargaining power of the FSU.

If the U.S. forms part of the abatement coalition, the issue of FSU-compliance won't matter at all for the NTR cases - neither in economic terms nor in environmental terms (FSU doesn't abate anyway!). However, U.S. withdrawal gives FSU a key leverage to achieve concessions from the remaining Annex-B countries: Without the U.S., the enactment of the Kyoto Protocol requires acceptance by FSU, because otherwise ratifying countries would not contribute at least $55 \%$ of the industrialized world's $\mathrm{CO}_{2}$ emissions in 1990.

Obviously, one key demand on behalf of FSU will be Annex B emissions trading without constraints from third parties on its permissible level of carbon exports.

\section{Withdrawal of the U.S. - Emissions Trading}

This leads us to the final set of core scenarios in which we consider the consequences of permit trading. As an outcome of the Bonn conference there are no (clear) limits on the extent to which one Annex B country can meet its reduction commitment by purchasing emission rights from other Annex B countries. Tables 6 and 7 show the implications of unconstrained Annex B emissions trading, which - after Bonn - appears as a very realistic option.

Full Annex B trading reduces the aggregate Annex B costs of implementing Kyoto dramatically due to the equalization of marginal abatement costs across regions. All OECD countries benefit substantially from purchasing cheap emission abatement in CEA and FSU. However, welfare costs for USA, CAN and AUN are still non-negligible in the scenarios in which the U.S. sticks to its Kyoto commitment. 
Table 6: Impacts of U.S. withdrawal for the TRD case and $O L D$ targets

\begin{tabular}{|c|c|c|c|c|c|c|}
\hline & \multicolumn{3}{|c|}{ Consumption (in \% vs. $B A U$ ) } & \multicolumn{3}{|c|}{ Marginal Abatement Costs (\$US/t C) } \\
\hline & USin_NTR & USin_TRD & USout_TRD & Usin_NTR & USin_TRD & USout_TRD \\
\hline USA & -0.67 & -0.40 & 0 & 170 & 61 & \\
\hline EUR & -0.44 & -0.16 & -0.03 & 168 & 61 & 7 \\
\hline JPN & -0.88 & -0.15 & -0.03 & 394 & 61 & 7 \\
\hline CAN & -1.81 & -0.92 & -0.10 & 193 & 61 & 7 \\
\hline AUN & -1.05 & -0.82 & -0.11 & 85 & 61 & 7 \\
\hline CEA & 0.68 & 1.40 & 0.09 & 0 & 61 & 7 \\
\hline FSU & -0.66 & 7.67 & 0.81 & 0 & 61 & 7 \\
\hline $\mathrm{CHN}$ & -0.09 & 0.03 & 0 & & & \\
\hline IND & 0.24 & 0.16 & 0.01 & & & \\
\hline MPC & -0.73 & -0.45 & -0.04 & & & \\
\hline ASI & 0.14 & 0.15 & 0.01 & & & \\
\hline ROW & -0.07 & -0.01 & 0 & & & \\
\hline TOTAL & -0.36 & -0.06 & 0 & & & \\
\hline NONAB & -0.08 & -0.03 & 0 & & & \\
\hline ANNEXB & -0.46 & -0.07 & 0 & & & \\
\hline \multirow[t]{3}{*}{ OECD } & -0.47 & -0.19 & -0.02 & & & \\
\hline & \multicolumn{3}{|c|}{$\mathrm{CO}_{2}$-Cut (in \% vs. $B A U$ ) } & \multicolumn{3}{|c|}{ Leakage $^{\mathrm{a}}$ (in \%) } \\
\hline & USin_NTR & USin_TRD & USout_TRD & Usin_NTR & USin_TRD & USout_TRD \\
\hline USA & 28.2 & 13.3 & -0.2 & & & 0.8 \\
\hline EUR & 18.2 & 7.5 & 1.1 & & & \\
\hline JPN & 28.3 & 7.4 & 1.2 & & & \\
\hline CAN & 28.9 & 12.4 & 2.2 & & & \\
\hline AUN & 16.8 & 13.4 & 2.1 & & & \\
\hline CEA & -4.9 & 17.9 & 2.8 & & & \\
\hline FSU & -4.8 & 16.7 & 2.6 & & & \\
\hline $\mathrm{CHN}$ & -1.4 & -1.3 & -0.2 & 2.5 & 2.2 & 0.6 \\
\hline IND & -1.5 & -1.1 & -0.1 & 0.6 & 0.4 & 0.1 \\
\hline MPC & -3.7 & -2.8 & -0.3 & 3 & 2.3 & 0.5 \\
\hline ASI & -3.8 & -2.5 & -0.3 & 2 & 1.4 & 0.3 \\
\hline ROW & -4.3 & -2.7 & -0.3 & 3.1 & 1.9 & 0.5 \\
\hline TOTAL & 9 & 5.8 & 0.5 & 11.1 & 8.2 & 2.8 \\
\hline
\end{tabular}

${ }^{a}$ Ratio of emission change in non-abating region over aggregate emission reduction in abating regions 
Table 7: Impacts of U.S. withdrawal for the TRD case and NEW targets

\begin{tabular}{|c|c|c|c|c|c|c|}
\hline & \multicolumn{3}{|c|}{ Consumption (in \% vs. $B A U$ ) } & \multicolumn{3}{|c|}{ Marginal Abatement Costs (\$US/t C) } \\
\hline & USin_NTR & USin_TRD & USout_TRD & USin_NTR & USin_TRD & USout_TRD \\
\hline USA & -0.52 & -0.25 & 0 & 143 & 39 & \\
\hline EUR & -0.34 & -0.09 & 0 & 139 & 39 & 0 \\
\hline JPN & -0.63 & -0.08 & 0 & 297 & 39 & 0 \\
\hline CAN & -1.03 & -0.47 & 0 & 108 & 39 & 0 \\
\hline AUN & -0.88 & -0.55 & 0 & 69 & 39 & 0 \\
\hline CEA & 0.57 & 0.93 & 0 & 0 & 39 & 0 \\
\hline FSU & -0.60 & 5.31 & 0 & 0 & 39 & 0 \\
\hline $\mathrm{CHN}$ & -0.07 & 0.02 & 0 & & & \\
\hline IND & 0.21 & 0.11 & 0 & & & \\
\hline MPC & -0.62 & -0.30 & 0 & & & \\
\hline ASI & 0.12 & 0.10 & 0 & & & \\
\hline ROW & -0.06 & -0.01 & 0 & & & \\
\hline TOTAL & -0.28 & -0.03 & 0 & & & \\
\hline NONAB & -0.07 & -0.02 & 0 & & & \\
\hline ANNEXB & -0.34 & -0.03 & 0 & & & \\
\hline \multirow[t]{3}{*}{ OECD } & -0.34 & -0.11 & 0 & & & \\
\hline & \multicolumn{3}{|c|}{$\mathrm{CO}_{2}$-Cut (in \% vs. $B A U$ ) } & \multicolumn{3}{|c|}{ Leakage $^{\mathrm{a}}$ (in \%) } \\
\hline & USin_NTR & USin_TRD & USout_TRD & USin_NTR & USin_TRD & USout_TRD \\
\hline USA & 25.2 & 9 & 0 & & & 0 \\
\hline EUR & 15.9 & 5 & 0 & & & \\
\hline JPN & 24.4 & 5 & 0 & & & \\
\hline CAN & 18.3 & 8.4 & 0 & & & \\
\hline AUN & 14.2 & 9.2 & 0 & & & \\
\hline CEA & -4.3 & 12.5 & 0 & & & \\
\hline FSU & -4.1 & 11.6 & 0 & & & \\
\hline $\mathrm{CHN}$ & -1.2 & -0.9 & 0 & 2.4 & 1.7 & 0 \\
\hline IND & -1.3 & -0.7 & 0 & 0.6 & 0.3 & 0 \\
\hline MPC & -3.2 & -1.9 & 0 & 2.9 & 1.7 & 0 \\
\hline ASI & -3.2 & -1.7 & 0 & 1.9 & 1 & 0 \\
\hline ROW & -3.7 & -1.8 & 0 & 3 & 1.5 & 0 \\
\hline TOTAL & 7.9 & 3.9 & 0 & 10.9 & 6.3 & 0 \\
\hline
\end{tabular}

${ }^{a}$ Ratio of emission change in non-abating region over aggregate emission reduction in abating regions 
Monetary transfers to CEA and FSU are large and provide major welfare gains, in particular to FSU. As expected, adoption of the less stringent emission reduction targets $(N E W)$ not only reduces the burden to OECD countries but also the benefits to CEA and FSU from permit trading: The decline in abatement demand of OECD countries drives down the price of tradable permits. Trade in emission rights reduces global leakage. However, global emission reduction under U.S. compliance drops by one third for the original Kyoto targets $(O L D)$ and by one half for the revised Kyoto targets $(N E W)$ as a consequence of hot air. This negative impact on global emission reduction should not obscure the fact that global emissions fall noticeably and average costs per emission reduction for abating OECD countries are much more favorable as compared to the cases without emission trading (USin_NTR and, in particular, USout_NTR).

U.S. withdrawal, joint with emissions trading between remaining Annex B countries, implies negligible costs for meeting the $O L D$ Kyoto targets and zero costs for meeting the $N E W$ Kyoto targets. Since the U.S. as the world largest potential buyer of emission rights drops off the permit market, the price of emission permits fall close to zero in the $O L D$ case. With relaxed Kyoto targets $(N E W)$, the permit price even hits zero, as the demand of remaining Annex-B countries is small relative to the supply of surplus emission rights from FSU and CEA. While U.S. withdrawal and unconstrained Annex B emissions trading sounds like good news from the aggregate cost side, the environmental effectiveness is more or less zero. To put it differently, Kyoto comes at no costs because the world economy and its emissions develop as in business-as-usual.

\section{Monopolistic Permit Supply}

Competitive behavior of FSU and CEA on the permit market may seem somewhat implausible for the case in which the international permit price falls to zero and emission sales therefore do not create any revenue. What will happen if these countries behave as monopolists restricting their supply in order to drive up the international carbon price? As a shortcut, we mimic such a behavior by imposing caps on emission right exports from FSU and CEA. Concretely, we assume that export quotas for FSU and CEA will be 0\%, 10\%, $20 \%, 30 \%, \ldots, 90 \%$, and $100 \%$ of the difference between their business-as-usual emissions and their emission entitlements after the Bonn updates. Table 8 summarizes reports results for non-compliance of the U.S. and otherwise unrestricted intra-OECD emissions trading. ${ }^{12}$

\footnotetext{
${ }^{12}$ Rents from export quotas accrue to FSU and CEA respectively.
} 
Table 8: Export quotas on hot air from FSU and CEA

\begin{tabular}{|c|c|c|c|c|c|c|c|c|c|c|c|c|}
\hline & USout_NTR_NEW & 0 & 10 & 20 & 30 & 40 & 50 & 60 & 70 & 80 & 90 & 100 \\
\hline & \multicolumn{12}{|c|}{ Consumption (in \% vs. BAU) } \\
\hline USA & 0.02 & 0.02 & 0.01 & 0.01 & 0.01 & 0.01 & 0 & 0 & 0 & 0 & 0 & 0 \\
\hline EUR & -0.42 & -0.45 & -0.40 & -0.35 & -0.29 & -0.24 & -0.18 & -0.12 & -0.06 & -0.01 & 0 & 0 \\
\hline JPN & -0.70 & -0.42 & -0.36 & -0.31 & -0.25 & -0.20 & -0.15 & -0.10 & -0.05 & -0.01 & 0 & 0 \\
\hline CAN & -0.46 & -0.48 & -0.49 & -0.47 & -0.43 & -0.38 & -0.30 & -0.22 & -0.12 & -0.01 & 0 & 0 \\
\hline AUN & -0.74 & -0.72 & -0.71 & -0.67 & -0.60 & -0.51 & -0.41 & -0.29 & -0.16 & -0.02 & 0 & 0 \\
\hline CEA & 0.28 & 0.28 & 0.40 & 0.46 & 0.47 & 0.44 & 0.37 & 0.28 & 0.16 & 0.02 & 0 & 0 \\
\hline FSU & -0.45 & -0.40 & 1.10 & 2.04 & 2.52 & 2.61 & 2.37 & 1.85 & 1.09 & 0.14 & 0 & 0 \\
\hline $\mathrm{CHN}$ & -0.07 & -0.04 & -0.03 & -0.03 & -0.02 & -0.02 & -0.01 & -0.01 & 0 & 0 & 0 & 0 \\
\hline IND & 0.07 & 0.07 & 0.06 & 0.05 & 0.04 & 0.03 & 0.02 & 0.02 & 0.01 & 0 & 0 & 0 \\
\hline MPC & -0.23 & -0.22 & -0.18 & -0.15 & -0.12 & -0.09 & -0.07 & -0.04 & -0.02 & 0 & 0 & 0 \\
\hline ASI & 0 & 0.04 & 0.04 & 0.03 & 0.03 & 0.02 & 0.02 & 0.01 & 0.01 & 0 & 0 & 0 \\
\hline $\mathrm{ROW}$ & -0.06 & -0.05 & -0.05 & -0.04 & -0.03 & -0.03 & -0.02 & -0.01 & -0.01 & 0 & 0 & 0 \\
\hline TOTAL & -0.19 & -0.16 & -0.13 & -0.10 & -0.07 & -0.05 & -0.04 & -0.02 & -0.01 & 0 & 0 & 0 \\
\hline NONAB & -0.02 & -0.01 & -0.01 & -0.01 & -0.01 & -0.01 & 0 & 0 & 0 & & 0 & 0 \\
\hline ANNEXB & -0.36 & -0.31 & -0.24 & -0.19 & -0.14 & -0.10 & -0.07 & -0.04 & -0.02 & 0 & 0 & 0 \\
\hline \multirow[t]{2}{*}{ OECD $^{1}$} & -0.37 & -0.32 & -0.28 & -0.25 & -0.21 & -0.17 & -0.13 & -0.09 & -0.05 & -0.01 & 0 & 0 \\
\hline & \multicolumn{12}{|c|}{ Marginal Abatement Costs (\$US/t C) } \\
\hline EUR & 130 & 141 & 117 & 95 & 75 & 57 & 41 & 26 & 13 & 2 & 0 & 0 \\
\hline JPN & 285 & 141 & 117 & 95 & 75 & 57 & 41 & 26 & 13 & 2 & 0 & 0 \\
\hline CAN & 83 & 141 & 117 & 95 & 75 & 57 & 41 & 26 & 13 & 2 & 0 & 0 \\
\hline \multirow[t]{2}{*}{ AUN } & 63 & 141 & 117 & 95 & 75 & 57 & 41 & 26 & 13 & 2 & 0 & 0 \\
\hline & \multicolumn{12}{|c|}{$\mathrm{CO}_{2}$-Cut (in \% vs. $B A U$ ) } \\
\hline USA & -1.6 & -1.6 & -1.4 & -1.2 & -1 & -0.8 & -0.6 & -0.4 & -0.2 & 0 & 0 & 0 \\
\hline EUR & 15.9 & 17 & 14.8 & 12.6 & 10.5 & 8.4 & 6.3 & 4.2 & 2.2 & 0.3 & 0 & 0 \\
\hline JPN & 24.4 & 15.8 & 13.9 & 12 & 10.1 & 8.2 & 6.2 & 4.3 & 2.3 & 0.3 & 0 & 0 \\
\hline CAN & 18.3 & 26.4 & 23.5 & 20.5 & 17.4 & 14.2 & 10.9 & 7.5 & 4 & 0.5 & 0 & 0 \\
\hline AUN & 14.2 & 26 & 23.2 & 20.3 & 17.2 & 14.1 & 10.9 & 7.6 & 4.1 & 0.5 & 0 & 0 \\
\hline CEA & -3.2 & -3.3 & -2.8 & -2.4 & -2 & -1.6 & -1.2 & -0.8 & -0.4 & 0 & 0 & 0 \\
\hline FSU & -3 & -3 & -2.8 & -2.6 & -2.3 & -1.9 & -1.5 & -1.1 & -0.6 & -0.1 & 0 & 0 \\
\hline $\mathrm{CHN}$ & -0.8 & -0.7 & -0.6 & -0.5 & -0.4 & -0.4 & -0.3 & -0.2 & -0.1 & 0 & 0 & 0 \\
\hline IND & -0.7 & -0.7 & -0.6 & -0.5 & -0.4 & -0.3 & -0.2 & -0.2 & -0.1 & 0 & 0 & 0 \\
\hline MPC & -1.5 & -1.6 & -1.3 & -1.1 & -0.9 & -0.7 & -0.5 & -0.3 & -0.2 & 0 & 0 & 0 \\
\hline ASI & -1.8 & -1.9 & -1.6 & -1.3 & -1.1 & -0.8 & -0.6 & -0.4 & -0.2 & 0 & 0 & 0 \\
\hline ROW & -2.3 & -2.4 & -2 & -1.7 & -1.4 & -1.1 & -0.9 & -0.6 & -0.3 & 0 & 0 & 0 \\
\hline \multirow[t]{2}{*}{ TOTAL } & 2.7 & 2.7 & 2.3 & 2 & 1.7 & 1.3 & 1 & 0.7 & 0.4 & 0 & 0 & 0 \\
\hline & \multicolumn{12}{|c|}{ Leakage $^{\mathrm{b}}$ (in $\%$ ) } \\
\hline USA & 8.8 & 9 & 7.8 & 6.7 & 5.6 & 4.5 & 3.4 & 2.3 & 1.2 & 0.1 & 0 & 0 \\
\hline $\mathrm{CHN}$ & 3.6 & 3.6 & 3.1 & 2.6 & 2.1 & 1.7 & 1.3 & 0.8 & 0.4 & 0.1 & 0 & 0 \\
\hline IND & 0.7 & 0.7 & 0.6 & 0.5 & 0.4 & 0.3 & 0.3 & 0.2 & 0.1 & 0 & 0 & 0 \\
\hline MPC & 3.4 & 3.4 & 2.9 & 2.3 & 1.9 & 1.4 & 1 & 0.7 & 0.3 & 0 & 0 & 0 \\
\hline ASI & 2.6 & 2.7 & 2.3 & 1.9 & 1.5 & 1.2 & 0.9 & 0.6 & 0.3 & 0 & 0 & 0 \\
\hline ROW & 4.5 & 4.6 & 4 & 3.4 & 2.8 & 2.2 & 1.7 & 1.1 & 0.6 & 0.1 & 0 & 0 \\
\hline TOTAL & 23.6 & 24 & 20.7 & 17.5 & 14.4 & 11.5 & 8.6 & 5.8 & 3 & 0.3 & 0 & 0 \\
\hline
\end{tabular}

${ }^{\mathrm{a}}$ N.B.: OECD does not include the U.S. (non-compliance case)

${ }^{\mathrm{b}}$ Ratio of emission change in non-abating region over aggregate emission reduction in abating regions 
We have also listed the results for the scenario USout_NTR_NEW to accommodate the direct comparison with the NTR case. Column "0" of Table 8 captures a situation in which FSU and CEA will not export any emission rights but intra-OECD emissions trading takes place. The latter cuts down compliance costs for the OECD aggregate by nearly $15 \%$ without loss of environmental effectiveness as compared to the no-emission-trading case (USout_NTR_NEW).

Comparison of regional welfare between USout_NTR_NEW and the Column "0" indicates that emissions trading does not lead to a Pareto improvement. This is a clear instance of terms-of-trade effects: Although it is known that - in the absence of second-best effects - emissions trading must improve global efficiency, there is no guarantee - a priori that every region will benefit from emissions trading. The reason behind this ambiguity are changes in the terms of trade which - contrary to the wide-spread partial equilibrium approach in environmental policy analysis - are taken into account in our general equilibrium framework.

When FSU and CEA sell hot air, the international price of carbon permits as well as total OECD compliance costs fall towards larger amounts of hot air exports. Column "100" of Table 8, where FSU and CEA sell off total hot air, coincides with the scenario USout_TRD_NEW in Table 6 with a permit price of zero and no changes as compared to $B A U$. Neither of the two extreme cases is attractive for FSU and CEA because they can not capitalize on sales of emission rights.

The numerical results indicate that FSU would aim at restricting permits sales at $40 \%$ of hot air in order to maximize welfare. ${ }^{13}$ In this case, OECD costs and global emission reduction drop roughly to half the value that arises for exclusive intra-OECD emissions trading. Table 8 illustrates the potential trade-offs between environmental effectiveness and total costs of OECD compliance on the one hand, as well as burden sharing between OECD and FSU/CEA on the other hand.

\section{Conclusions}

In this paper, we investigated different scenarios for implementing the Kyoto Protocol combining alternative options along three important policy dimensions: U.S. compliance

\footnotetext{
${ }^{13}$ Note that CEA prefers a slightly more restrictive export quota regime because the foregone revenues from permit sales would be more than offset from terms-of-trade gains on fossil fuel markets due to the larger fall in international fuel prices.
} 
versus U.S. withdrawal, domestic action versus unrestricted Annex B emissions trading, and the original Kyoto targets versus the relaxed targets of Bonn.

Our results clearly indicate that U.S. withdrawal from the Protocol implies a dramatic reduction in environmental effectiveness. If emission trading among remaining Annex-B countries becomes more or less unrestricted, which seems to be rather likely after the Bonn outcome, the reduction of global carbon emissions as compared to $B A U$ will fall to zero. The reason is that supply of surplus emission rights from Russia, Ukraine, and Eastern Europe is large relative to the demand from OECD countries other than the U.S., driving down the permit price close to zero (if Kyoto targets had not been relaxed for sink credits) or to zero (if Kyoto targets are updated with sink credits).

If remaining OECD countries would opt for strictly domestic action in order to prevent hot air, global carbon emissions could be reduced by $2.7 \%$ (with sink credits) or $3.1 \%$ (without sink credits). However, the global emission cutback would then only amount to roughly a third of the value that could be achieved for U.S. compliance while remaining OECD countries would suffer more or less the same non-negligible adjustment costs. Implicit willingness-to-pay, thus, would have to triple in these countries. Such a policy appears rather unacceptable to citizens in non-U.S. OECD countries - not only with regard to overall costeffectiveness but also with respect to fairness considerations.

Monopolistic permit supply by Russia, Ukraine and Eastern Europe may suppress a larger share of hot air and halve compliance costs of abating OECD countries as compared to strictly domestic action. However, environmental effectiveness falls too, with a global emission reduction around $1 \%$ for the revised Kyoto targets.

Policy makers have welcomed the outcome of the Bonn climate negotiations as a decisive breakthrough in international climate politics. The environmental effects can not be the reason for celebration: Sink credits, hot air through emissions trading and, in particular, the continued U.S. withdrawal will make Kyoto ineffective in environmental terms.

Nevertheless, it can be argued that - even without any effective emission cutback - the ratification of Kyoto is crucial for the further policy process of climate protection. Failure might have thrown back the efforts to climate protection by several years. Hopes remain that the U.S. might rejoin the Protocol under the new conditions. Compliance costs to the U.S. economy seem rather moderate, which could enhance the domestic U.S. political pressure in favor of coordinated international abatement. Starting from a ratified Kyoto Protocol, it will be also much easier to achieve effective GHG emission reduction in the second commitment period of the Kyoto Protocol after 2012. 


\section{References}

Bernstein, P., D. Montgomery, T. F. Rutherford and G. Yang (1999), Effects of Restrictions on International Permit Trading: The MS-MRT Model, The Energy Journal - Special Issue, 221-257.

Bergmann, L. (1990), The Development of Computable General Equilibrium Models, in Bergman, L., D. W. Jorgenson and E. Zalai (eds): General Equilibrium Modeling and Economic Policy Analysis, Cambridge, 3-30.

Böhringer, C. (2000), Cooling Down Hot Air - A Global CGE Analysis of Post-Kyoto Carbon Abatement Strategies, Energy Policy, 28, 779-789.

Böhringer, C. and T. F. Rutherford (2001), Carbon Abatement and International Spillovers, Environmental and Resource Economics (forthcoming).

Böhringer C. and C. Vogt (2001), Internationaler Klimaschutz - nicht mehr als symbolische Politik?, Aussenwirtschaft 56 (II), 139-155.

Böhringer, C., J. Jensen and T. F. Rutherford (2000), Energy Market Projections and Differentiated Carbon Abatement in the European Union, in C. Carraro (ed), Efficiency and Equity of Climate Change Policy, Dordrecht: Kluwer Academic Publishers, 199220.

Bollen, J., A. Gielen and H. Timmer (1999), Clubs, Ceilings and CDM - Macroeconomics of Compliance with the Kyoto Protocol, The Energy Journal - Special Issue, 177-206.

Criqui, P., S. Mima and L. Viguier (1999), Marginal abatement costs of CO2 emission reductions, geographical flexibility and concrete ceilings: an assessment using the POLES model, Energy Policy, 27 (10), 585-602.

DOE (1998), Department of Energy, Annual Energy Outlook (AEO 1998), Energy Information Administration, http://www.eia.doe.gov.

Ellerman, A.D. and I. S. Wing (2000), Supplemantarity: An Invitation for Monopsony, The Energy Journal, 21 (4), 29-59.

Grubb, M., J. Edmonds, P. ten Brink and M. Morrison (1993), The Costs of Limiting Fossilfuel $\mathrm{CO}_{2}$ Emissions: A Survey and Analysis, Annual Review of Energy and Environment, 18, 397-478.

IEA(1996), International Energy Agency, Energy Prices and Taxes, Energy Balances of OECD and Non-OECD Countries, Paris: IEA publications.

McDougall, R. A., A. Elbehri and T. P. Truong (1998), Global Trade Assistance and Protection: The GTAP4 Data Base, Center for Global Trade Analysis, Purdue University, West Lafayette. 
Paltsev, S.V. (2000), The Kyoto Protocol: Hot Air for Russia?, University of Colorado, Working Paper 00-9, http://debreu.colorado.edu/projects/sergey hotair.pdf

Paltsev, S.V. (2001), The Kyoto Protocol: Regional and Sectoral Contributions to the Carbon Leakage, Energy Journal, 22 (4), 53-79.

Rutherford, T.F. and S.V. Paltsev (2000), GTAP-Energy in GAMS, University of Colorado, Working Paper 00-2, http://debreu.colorado.edu/download/gtap-eg.html

UNEP (2001), United Nations Environmental Program, International Panel on Climate Change, Climate Change 2001: Mitigation, Contribution of Working Group III to the Third Assessment Report of the Intergovernmental Panel on Climate Change, Cambridge: Cambridge University Press.

UNFCCC (1997), United Nations Framework Convention on Climate Change, Kyoto Protocol to the United Nations Framework Convention on Climate Change, FCCC/CP/L.7/Add.1, Kyoto.

UNFCCC (2001), United Nations Framework Convention on Climate, Review of the implementation of commitments and of other provisions of the Convention, FCCC/CP/2001/L.7, VI, 5.

Weyant, J. (ed) (1999), The Costs of the Kyoto Protocol: A Multi-Model Evaluation, The Energy Journal, Special Issue. 


\section{Appendix A: Detailed Algebraic Model Description}

This section outlines the main characteristics of a generic static general equilibrium model of the world economy designed for the medium-run economic analysis of carbon abatement constraints. It is a well-known Arrow-Debreu model that concerns the interaction of consumers and producers in markets. Consumers in the model have a primary exogenous endowment of the commodities and a set of preferences giving demand functions for each commodity. The demands depend on all prices; they are continuous and non-negative, homogenous of degree zero in factor prices and satisfy Walras' Law, i.e. the total value of consumer expenditure equals consumer income at any set of prices. Market demands are the sum of final and intermediate demands. Producers maximize profits given a constant returns to scale production technology. Because of the homogeneity of degree zero of the demand functions and the linear homogeneity of the profit functions in prices, only relative prices matter in such a model. Two classes of conditions characterize the competitive equilibrium in the model: market clearance conditions and zero profit conditions. In equilibrium, price levels and production levels in each industry are such that market demand equals market supply for each commodity. Profit maximization under a constant returns to scale technology implies that no activity does any better than break even at equilibrium prices. The model is a system of simultaneous, non-linear equations with the number of equations equal to the number of variables.

\section{A.1 Production}

Within each region (indexed by the subscript $r$ ), each producing sector (indexed interchangeable by $i$ and $j$ ) is represented by a single-output producing firm which chooses input and output quantities in order to maximize profits. Firm behavior can be construed as a two-stage procedure in which the firm selects the optimal quantities of primary factors $k$ (indexed by $f$ ) and intermediate inputs $x$ from other sectors in order to minimize production costs given input prices and some production level $Y$ with $Y=\varphi(k, x)$ the production functions. The second stage, given an exogenous output price, is the selection of the output level $Y$ to maximize profits. The firm's problem is then:

$$
\underset{y_{j i r}, x_{j i r}, k_{f i r}}{\operatorname{Max}} \Pi_{i r}=p_{i r} \cdot Y_{i r}-C_{i r}\left(p_{j r}, w_{f r}, Y_{i r}\right) \text { s.t. } Y_{i r}=\varphi_{i r}\left(x_{j i r}, k_{f i r}\right)
$$


where $\Pi$ denotes the profit functions, $\mathrm{C}$ the cost functions which relate the minimum possible total costs of producing $\mathrm{Y}$ to the positive input prices, technology parameters, and the output quantity $\mathrm{Y}$, and $\mathrm{p}$ and $\mathrm{w}$ are the prices for goods and factors, respectively.

Production of each good takes place according to constant elasticity of substitution (CES) production functions, which exhibit constant returns to scale. Therefore, the output price equals the per-unit cost in each sector, and firms make zero profits in equilibrium (Euler's Theorem). Profit maximization under constant returns to scale implies the equilibrium condition:

$$
\pi_{i r}=p_{i r}-c_{i r}\left(p_{j r}, w_{f r}\right)=0 \quad \text { (zero profit condition) }
$$

where $c$ and $\pi$ are the unit cost and profit functions, respectively.

Demand functions for goods and factors can be derived by Shepard's Lemma. It suggests that the first-order differentiation of the cost function with respect to an input price yields the cost-minimizing demand function for the corresponding input. Hence, the intermediate demand for $\operatorname{good} j$ in sector $i$ is:

$$
x_{j i r}=\frac{\partial C_{i r}}{\partial p_{j r}}=Y_{i r} \cdot \frac{\partial c_{i r}}{\partial p_{j r}}
$$

and the demand for factor $f$ in sector $i$ is:

$$
k_{f i r}=\frac{\partial C_{i r}}{\partial w_{f r}}=Y_{i r} \cdot \frac{\partial c_{i r}}{\partial w_{f r}}
$$

The profit functions posses a corresponding derivative property (Hotelling's Lemma):

$$
x_{j i r}=\frac{\partial \Pi_{i r}}{\partial p_{j r}}=Y_{i r} \cdot \frac{\partial \pi_{i r}}{\partial p_{j r}} \text { and } k_{f i r}=\frac{\partial \Pi_{i r}}{\partial w_{f r}}=Y_{i r} \cdot \frac{\partial \pi_{i r}}{\partial w_{f r}}
$$

The variable, price dependent input coefficients, which appear subsequently in the market clearance conditions, are thus: 


$$
a_{j i r}^{x}=\frac{\partial c_{i r}}{\partial p_{j r}}=\frac{\partial \pi_{i r}}{\partial p_{j r}} \text { and } a_{f i r}^{k}=\frac{\partial c_{i r}}{\partial w_{f r}}=\frac{\partial \pi_{i r}}{\partial w_{f r}}
$$

The model captures the production of commodities by aggregate, hierarchical (or nested) constant elasticity of substitution (CES) production functions that characterize the technology through substitution possibilities between capital, labor, energy and material (nonenergy) intermediate inputs (KLEM). Two types of production functions are employed: those for fossil fuels (in our case $v=\mathrm{COL}, \mathrm{CRU}, \mathrm{GAS}$ ) and those for non-fossil fuels (in our case $n$ $=$ EIS, ELE, OIL, ROI).

Figure A.1 illustrates the nesting structure in non-fossil fuel production. In the production of non-fossil fuels $n r$, non-energy intermediate inputs $M$ (used in fixed coefficients among themselves) are employed in (Leontief) fixed proportions with an aggregate of capital, labor and energy at the top level. At the second level, a CES function describes the substitution possibilities between the aggregate energy input $E$ and the value-added aggregate $K L$ (For the sake of simplicity, the symbols $\alpha, \beta, \phi$ and $\theta$ are used throughout the model description to denote the technology coefficients.):

$$
Y_{n r}=\min \left\{\left(1-\theta_{n r}\right) M_{n r}, \theta_{n r} \phi_{n r}\left[\alpha_{n r} E_{n r}^{\rho^{K L E}}+\beta_{n r} K L_{n r}^{\rho^{K L E}}\right]^{1 / \rho^{K L E}}\right\}
$$

with $\sigma^{K L E}=1 /\left(1-\rho^{K L E}\right)$ the elasticity of substitution between energy and the primary factor aggregate and $\theta$ the input (Leontief) coefficient. Finally, at the third level, capital and labor factor inputs trade-off with a constant elasticity of substitution $\sigma^{K L}$ :

$$
K L_{n r}=\phi_{n r}\left[\alpha_{n r} K_{n r}^{\rho^{K L}}+\beta_{n r} L_{n r}^{\rho^{K L}}\right]^{1 / \rho^{K L}}
$$

As to the formation of the energy aggregate $E$, we employ several levels of nesting to represent differences in substitution possibilities between primary fossil fuel types as well as substitution between the primary fossil fuel composite and secondary energy, i.e. electricity. The energy aggregate is a CES composite of electricity and primary energy inputs $F F$ with elasticity $\sigma^{E}=1 /\left(1-\rho^{E}\right)$ at the top nest: 


$$
E_{n r}=\phi_{n r}\left[\alpha_{n r} E L E_{n r}^{\rho^{E}}+\beta_{n r} F F_{n r}^{\rho^{E}}\right]^{1 / \rho^{E}}
$$

The primary energy composite is defined as a CES function of coal and the composite of refined oil and natural gas with elasticity $\sigma^{C O A}=1 /\left(1-\rho^{C O A}\right)$. The oil-gas composite is assumed to have a simple Cobb-Douglas functional form with value shares given by $\theta$ :

$$
F F_{n r}=\phi_{n r}\left[\alpha_{n r} C O A_{n r}^{\rho^{C O A}}+\beta_{n r}\left(O I L^{\theta_{n r}} \cdot G A S^{1-\theta_{n r}}\right)^{\rho^{C O A}}\right]^{1 / \rho^{C O A}} .
$$

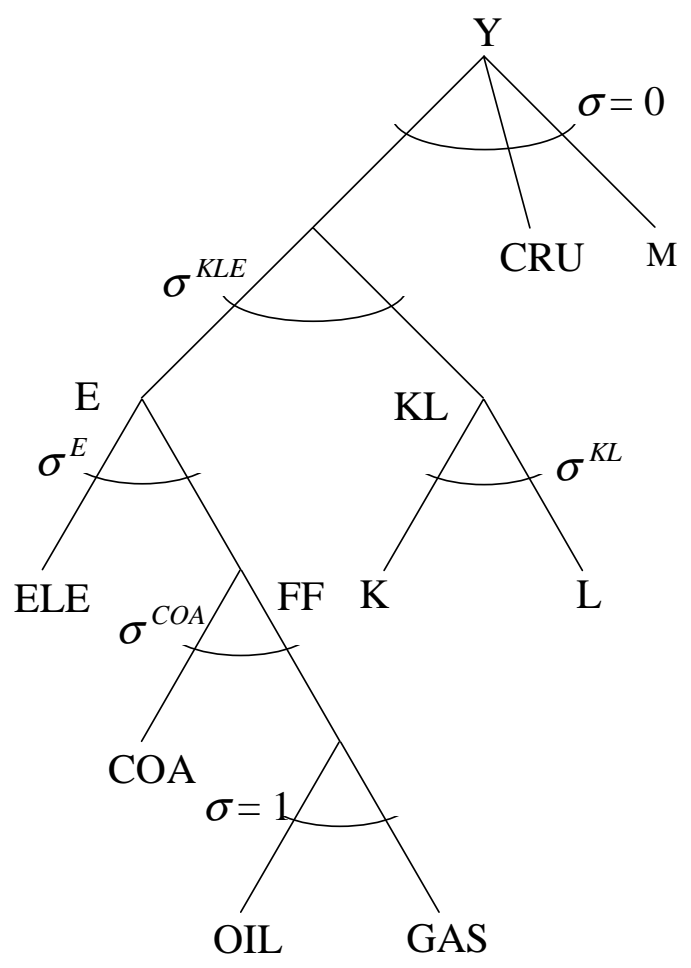

Figure A.1: Nesting structure of non-fossil fuel production

Fossil fuel resources $v$ are modeled as graded resources. The structure of production of fossil fuels is given in Figure A.2. It is characterized by the presence of a fossil fuel resource in fixed supply. All inputs, except for the sector-specific resource R, are aggregated in fixed proportions at the lower nest. Mine managers minimize production costs subject to the technology constraint: 


$$
Y_{v r}=\phi_{v r}\left[\alpha_{v r} R_{v r}^{\rho_{v}^{f}}+\beta_{v r}\left[\min \left(\theta_{v r}^{K} K_{v r}, \theta_{v r}^{L} L_{v r}, \theta_{v r}^{E} E_{v r}, \theta_{v r}^{M} M_{j v r}\right)\right]^{\rho_{v}^{f}}\right]^{1 / \rho_{v}^{f}}
$$

The resource grade structure is reflected by the elasticity of substitution between the fossil fuel resource and the capital-labor-energy-material aggregate in production. The substitution elasticity between the specific factor and the Leontief composite at the top level is $\sigma_{v r}^{f}=1 /\left(1-\rho_{v r}{ }^{f}\right)$. This substitution elasticity is calibrated in consistency with an exogenously given supply elasticity of fossil fuel $\varepsilon_{v r}$ according to

$$
\varepsilon_{v r}=\frac{1-\gamma_{v r}}{\gamma_{v r}} \sigma_{v r}^{f}
$$

with $\gamma$ vr the resource value share.

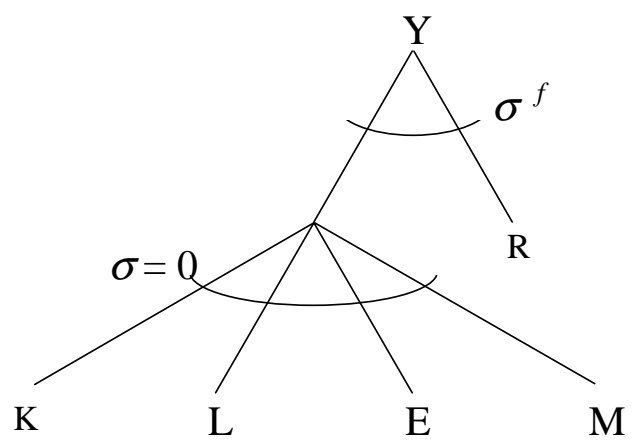

Figure A.2: Nesting structure for fossil fuel production

We now turn to the derivation of the factor demand functions for the nested CES production functions, taking into account the duality between the production function and the cost function The total cost function that reflects the same production technology as the CES production function for e.g. value added $K L$ in non-fossil fuel production given by [8] is:

$$
C_{n r}^{K L}=\frac{1}{\phi_{n r}}\left[\alpha_{n r}^{\sigma^{K L}} P K_{n r}^{1-\sigma^{K L}}+\beta_{n r}^{\sigma^{K L}} P L_{n r}^{1-\sigma^{K L}}\right]^{1 /\left(1-\sigma^{K L}\right)} \cdot K L_{n r}
$$


where PK and PL are the per-unit factor costs for the industry including factor taxes if applicable. The price function for the value-added aggregate at the third level is:

$$
P K L_{n r}=\frac{1}{\phi_{n r}}\left[\alpha_{n r}^{\sigma^{K L}} P K_{n r}^{1-\sigma^{K L}}+\beta_{n r}^{\sigma^{K L}} P L_{n r}^{1-\sigma^{K L}}\right]^{1 /\left(1-\sigma^{K L}\right)}=c_{n r}^{K L}
$$

Shepard's Lemma gives the price-dependent composition of the value-added aggregate as:

$$
\frac{K_{n r}}{K L_{n r}}=\phi_{n r}^{\sigma^{K L}-1}\left(\alpha_{n r} \cdot \frac{P K L_{n r}}{P K_{n r}}\right)^{\sigma^{K L}}, \frac{L_{n r}}{K L_{n r}}=\phi_{n r}^{\sigma^{K L}-1}\left(\beta_{n r} \cdot \frac{P K L_{n r}}{P L_{n r}}\right)^{\sigma^{K L}}
$$

In order to determine the variable input coefficient for capital and labor $a_{n r}{ }^{K}=K_{n r} / Y_{n r}$ and $a_{n r}{ }^{L}=L_{n r} / Y_{n r}$, one has to multiply

[15] with the per unit demand for the value added aggregate $K L_{n r} / Y_{n r}$, which can be derived in an analogous manner. The cost function associated with the production function [7] is:

$$
P Y_{n r}=\left(1-\theta_{n r}\right) P M_{n r}+\frac{\theta_{n r}}{\hat{\phi}_{n r}}\left[\begin{array}{ccc}
\alpha_{n r} \sigma^{K L E} & P E_{n r}^{1-\sigma^{K L E}}+\varlimsup_{n r}^{\sigma^{K L E}} & P K L_{n r}^{1-\sigma^{K L E}}
\end{array}\right]^{\frac{1}{1-\sigma^{K L E}}}
$$

and

$$
\frac{K L_{n r}}{Y_{n r}}=\theta_{n r} \hat{\phi}_{n r}^{\sigma^{K L E}-1}\left(\beta_{n r} \cdot \frac{P Y_{n r}}{P K L_{n r}}\right)^{\sigma^{K L E}}
$$

with $\theta_{n r}$ the $K L E$ value share in total production. The variable input coefficient for e.g. labor is then:

$$
a_{n r}^{L}=\theta_{n r} \phi_{n r}^{\sigma^{K L}-1} \hat{\phi}_{n r}^{\sigma^{K L E}-1}\left(\beta_{n r} \cdot \frac{P K L_{n r}}{P L_{n r}}\right)^{\sigma^{K L}}\left(\beta_{n r} \cdot \frac{P Y_{n r}}{P K L_{n r}}\right)^{\sigma^{K L E}}
$$




\section{A.2 Households}

In each region, private demand for goods and services is derived from utility maximization of a representative household subject to a budget constraint given by the income level INC. The agent is endowed with the supplies of the primary factors of production (natural resources used for fossil fuel production, labor and capital) and tax revenues. In our comparative-static framework, overall investment demand is fixed at the reference level. The household's problem is then:

$$
\underset{d_{i r}}{\operatorname{Max}} W_{r}\left(d_{i r}\right) \text { s.t. } I N C_{r}=\sum_{f} w_{f r} \bar{k}_{f r}+T R_{r}=\sum_{i} p_{i r} d_{i r}
$$

where $W$ is the welfare of the representative household in region $r, d$ denotes the final demand for commodities, $\bar{k}$ is the aggregate factor endowment of the representative agent and $T R$ are total tax revenues. Household preferences are characterized by a CES utility function. As in production, the maximization problem in [1] can thus be expressed in form of an unit expenditure function $e$ or welfare price index $p w$, given by:

$$
p w_{r}=e_{r}\left(p_{i r}\right)
$$

Compensated final demand functions are derived from Roy's Identity as:

$$
d_{i r}=\overline{I N C}_{r} \frac{\partial e_{r}}{\partial p_{i r}}
$$

with $\overline{I N C}$ the initial level of expenditures.

In the model, welfare of the representative agent is represented as a CES composite of a fossil fuel aggregate and a non-fossil fuel consumption bundle. Substitution patterns within the latter are reflected via a Cobb-Douglas function. The fossil fuel aggregate in final demand consists of the various fossil fuels ( $f e=\mathrm{COL}, \mathrm{OIL}, \mathrm{GAS})$ trading off at a constant elasticity of substitution. The CES utility function is:

$$
U_{r}=\left[\alpha_{r}\left(\sum_{f e} \beta_{f e, r} C_{f e, r}^{\rho^{F}}\right)^{\rho^{C} / \rho^{F}}+\phi_{r}\left(\prod_{j \notin f e} C_{j r}^{\theta_{j}}\right)^{\rho^{C}}\right]^{1 / \rho^{C}}
$$


where the elasticity of substitution between energy and non-energy composites is given by $\sigma_{C}=1 /\left(1-\rho_{C}\right)$, the elasticity of substitution within the fossil fuel aggregate by $\sigma_{F E}=$ $1 /\left(1-\rho_{F E}\right)$, and $\theta_{j}$ are the value shares in non-fossil fuel consumption. The structure of final demand is presented in Figure A.3.

Total income of the representative agent consists of factor income, revenues from taxes levied on output, intermediate inputs, exports and imports, final demand as well as tax revenues from $\mathrm{CO}_{2}$ taxes (TR) and a baseline exogenous capital flow representing the balance of payment deficits $B$ less expenses for exogenous total investment demand PI.I. The government activity is financed through lump-sum levies. It does not enter the utility function and is hence exogenous in the model. The budget constraint is then given by:

$$
P C_{r} \cdot C_{r}=P L_{r} \cdot \bar{L}_{r}+P K_{r} \cdot \bar{K}_{r}+\sum_{v} P R_{v r} \cdot \bar{R}_{v r}+T R_{r}+\bar{B}_{r}-P I_{r} \cdot I_{r}
$$

with $C$ the aggregate household consumption in region $r$ and $P C$ its associated price.

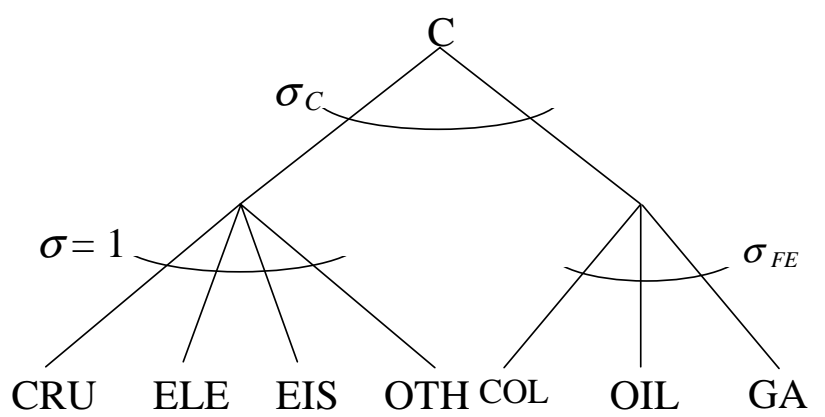

Figure A.3: Structure of household demand

\section{A.3 Foreign Trade}

All commodities are traded in world markets. Crude oil and coal are imported and exported as a homogeneous product, reflecting empirical evidence that these fossil fuel markets are rather integrated due to cheap shipping possibilities. All other goods are characterized by product differentiation. There is imperfect transformability (between exports and domestic sales of domestic output) and imperfect substitutability (between imports and domestically sold domestic output). Bilateral trade flows are subject to export taxes, tariffs and transportation 
costs and calibrated to the base year 1995. There is an imposed balance of payment constraint to ensure trade balance, which is warranted through flexible exchange rates, incorporating the benchmark trade deficit or surplus for each region.

On the output side, two types of differentiated goods are produced as joint products for sale in the domestic markets and the export markets, respectively. The allocation of output between domestic sales $D$ and international sales $X$ is characterized by a constant elasticity of transformation (CET) function. Hence, firms maximize profits subject to the constraint:

$$
Y_{i r}=\phi_{i r}\left[\alpha_{i r} D_{i r}^{\eta}+\beta_{i r} X_{i r}^{\eta}\right]^{1 / \eta}
$$

with $\sigma^{t r}=1 /(1+\eta)$ the transformation elasticity.

Regarding imports, the standard Armington convention is adopted in the sense that imported and domestically produced goods of the same kind are treated as incomplete substitutes (i. e. wine from France is different from Italian wine). The aggregate amount of each (Armington) good $A$ is divided among imports and domestic production:

$$
A_{i r}=\phi_{i r}\left[\alpha_{i r} D_{i r}^{\rho^{D}}+\beta_{i r} M_{i r}^{\rho^{D}}\right]^{1 / \rho^{D}}
$$

In this expression $\sigma^{D}=1 /\left(1-\rho^{D}\right)$ is the Armington elasticity between domestic and imported varieties. Imports $M$ are allocated among import regions $s$ according to a CES function:

$$
M_{i r}=\phi_{i r}\left[\sum_{s} \alpha_{i r} X_{i s r}^{\rho^{M}}\right]^{1 / \rho^{M}}
$$

with $X$ the amount of exports from region s to region $\mathrm{r}$ and $\sigma^{M}=1 /\left(1-\rho^{M}\right)$ the Armington elasticity among imported varieties. Intermediate as well as final demands are, hence, (nested CES) Armington composites of domestic and imported varieties.

The assumption of product differentiation permit the model to match bilateral trade with cross-hauling of trade and avoids unrealistically strong specialization effects in response to exogenous changes in trade (tax) policy. On the other hand, the results may then be sensitive to the particular commodity and regional aggregation chosen in the model. 


\section{A.4 Carbon emissions}

Carbon emissions are associated with fossil fuel consumption in production, investment, government and private demand. Carbon is treated as a Leontief (fixed coefficient) input into production and consumption activities. Each unit of a fuel emits a known amount of carbon where different fuels have different carbon intensities. The applied carbon coefficients are 25 MT carbon per EJ for coal, 14 MT carbon per EJ for gas and 20 MT carbon per EJ for refined oil.

Carbon policies are introduced via an additional constraint that holds carbon emissions to a specified limit. The solution of the model gives a shadow value on carbon associated with this carbon constraint. This dual variable or shadow price can be interpreted as the price of carbon permits in a carbon permit system or as the $\mathrm{CO} 2$ tax that would induce the carbon constraint in the model. The shadow value of the carbon constraint equals the marginal cost of reduction. It indicates the incremental cost of reducing carbon at the carbon constraint. The total costs represent the resource cost or dead-weight loss to the economy of imposing carbon constraints. Carbon emission constraints induce substitution of fossil fuels with less expensive energy sources (fuel switching) or employment of less energy-intensive manufacturing and production techniques (energy savings). The only means of abatement are hence inter-fuel and fuel-/non-fuel substitution or the reduction of intermediate and final consumption.

Given an emission constraint producers as well as consumers must pay this price on the emissions resulting from the production and consumption processes. Revenues coming from the imposition of the carbon constraint are given to the representative agent. The total cost of Armington inputs in production and consumption that reflects the CES production technology in [25] but takes $\mathrm{CO} 2$ emission restrictions into account is:

$$
C_{i r}^{A}=\left[\left(\alpha_{i r}^{\sigma^{D}} P D_{i r}^{1-\sigma^{D}}+\beta_{i r}^{\sigma^{A}} P M_{i r}^{1-\sigma^{D}}\right)^{1 /\left(1-\sigma^{D}\right)}+\tau_{r} \cdot a_{i}\right] \cdot A_{i r}
$$

with $a_{i}$ the carbon emissions coefficient for fossil fuel $i$ and $\tau$ the shadow price of $\mathrm{CO}_{2}$ in region $r$ associated with the carbon emission restriction:

$$
\overline{\mathrm{CO}}_{r}=\sum_{i} A_{i r} \cdot a_{i}
$$


where $\overline{\mathrm{CO}}_{r}$ is the endowment of carbon emission rights in region $\mathrm{r}$.

\section{A.5 Zero Profit and Market Clearance Conditions}

The equilibrium conditions in the model are zero profit and market clearance conditions. Zero profit conditions as derived in [2] require that no producer earns an "excess" profit in equilibrium. The value of inputs per unit activity must be equal to the value of outputs. The zero profit conditions for production, using the variable input coefficient derived above, is:

$$
P K \cdot a_{i r}^{K} \cdot Y_{i r}+P L \cdot a_{i r}^{L} \cdot Y_{i r}+\sum_{j} P A_{j} \cdot a_{j i r}^{M} \cdot Y_{i r}=P Y_{i r} \cdot Y_{i r} .
$$

The market clearance conditions state that market demand equals market supply for all inputs and outputs. Market clearance conditions have to hold in equilibrium. Domestic markets clear, equating aggregate domestic output plus imports, i.e. total Armington good supply, to aggregate demand, which consists of intermediate demand, final demand, investment and government demand:

$$
A_{i r}=\sum_{j} Y_{j r} \frac{\partial \pi_{j r}^{Y}}{\partial P A_{i r}}+C_{r} \frac{\partial e_{r}}{\partial P A_{i r}}
$$

with $P A$ the price of the Armington composite. $\pi_{i r}{ }^{Z}$ is the per unit zero profit function with $Z$ the name assigned to the associated production activity. The derivation of $\pi_{i r}{ }^{Z}$, with respect to input and output prices, yields the compensated demand and supply coefficients, e.g. $\partial \pi_{j r}{ }^{Y} / \partial P A_{i r}=a_{i j r}{ }^{A}$ the intermediate demand for Armington good $i$ in sector $j$ of region $r$ per unit of output $Y$. Output for the domestic market equals total domestic demand:

$$
Y_{i r} \frac{\partial \pi_{i r}^{Y}}{\partial P D_{i r}}=\sum_{j} A_{j r} \frac{\partial \pi_{j r}^{A}}{\partial P D_{i r}}
$$

with $P D$ the domestic commodity price. Export supply equals import demand across all trading partners:

$$
Y_{i r} \frac{\partial \pi_{i r}^{Y}}{\partial P X_{i r}}=\sum_{s} M_{i s} \frac{\partial \pi_{i s}^{M}}{\partial P X_{i r}}
$$


with $P X$ the export price. Aggregate import supply equals total import demand:

$$
M_{i r}=A_{i r} \frac{\partial \pi_{i r}^{A}}{\partial P M_{i r}}
$$

where $P M$ is the import price.

Primary factor endowment equals primary factor demand:

$$
\begin{aligned}
& \bar{L}_{r}=\sum_{i} Y_{i r} \frac{\partial \pi_{i r}^{Y}}{\partial P L_{r}}, \\
& \bar{K}_{r}=\sum_{i} Y_{i r} \frac{\partial \pi_{i r}^{Y}}{\partial P K_{r}}, \\
& \bar{R}_{v r}=Y_{v r} \frac{\partial \pi_{v r}^{Y}}{\partial P R_{v r}} .
\end{aligned}
$$

An equilibrium is characterized by a set of prices in the different goods and factor markets such that the zero profit and market clearance conditions stated above hold. 


\section{A.6 Overview of Elasticities}

Table A.1 provides a summary of elasticity values adopted for the core simulations.

Table A.1: Default values of key substitution and supply elasticities

Description Value

Substitution elasticities in non-fossil fuel production

$\sigma^{K L E} \quad$ Energy vs. value added $\quad 0.8$

$\sigma^{K L} \quad$ Capital vs. labor $\quad 1.0$

$\sigma^{E} \quad$ Electricity vs. primary energy inputs $\quad 0.3$

$\sigma^{C O L}$ Coal vs. gas-oil $\quad 0.5$

Substitution elasticities in final demand

$\sigma_{C} \quad$ Fossil fuels vs. non-fossil fuels $\quad 0.8$

$\sigma_{F E} \quad$ Fossil fuels vs. fossil fuels $\quad 0.3$

Elasticities in international trade (Armington)

$\sigma^{D} \quad$ Substitution elasticity between imports vs. $\quad 4.0$ domestic inputs

$\sigma^{M} \quad$ Substitution elasticity between imports vs. $\quad 8.0$ imports

$\sigma^{t r} \quad$ Transformation elasticity domestic vs. export $\quad 2.0$

Exogenous supply elasticities of fossil fuels $\mathcal{E}$

Crude oil $\quad 1.0$

Coal $\quad 0.5$

$\begin{array}{ll}\text { Natural gas } & 1.0\end{array}$ 


\section{Appendix B: Regional and Sectoral Aggregation}

The model is calibrated to the energy-economy data set GTAP-EG which combines economic data from the Global Trade Analysis Project (GTAP) database with energy flows and energy prices form OECD International Energy Agency (IEA) statistics (Rutherford and Paltsev 2000). The GTAP-EG data set encompasses 45 regions and 22 goods/sectors (5 of which are energy goods/sectors) as listed in Tables B.1 and B.2. Regions and sectors of the original GTAP-EG data set are aggregated according to Tables B.3 and B.4 to yield the model's regions and sectors.

Table B.1: Regions in GTAP-EG

\begin{tabular}{llll}
\hline ARG & Argentina & MYS & Malaysia \\
AUS & Australia & NZL & New Zealand \\
BRA & Brazil & PHL & Philippines \\
CAM & Central America and Caribbean & RAP & Rest of Andean Pact \\
CAN & Canada & RAS & Rest of South Asia \\
CEA & Central European Associates & REU & Rest of EU \\
CHL & Chile & RME & Rest of Middle East \\
CHN & China & RNF & Rest of North Africa \\
COL & Columbia & ROW & Rest of World \\
DEU & Germany & RSA & Rest of South Africa \\
DNK & Denmark & RSM & Rest of South America \\
EFT & European Free Trade Area & RSS & Rest of South-Saharan Africa \\
FIN & Finland & SAF & South Africa \\
FSU & Former Soviet Union & SGP & Singapore \\
GBR & United Kingdom & SWE & Sweden \\
HKG & Hong Kong & THA & Thailand \\
IDN & Indonesia & TUR & Turkey \\
IND & India & TWN & Taiwan \\
JPN & Japan & URY & Uruguay \\
KOR & Republic of Korea & USA & United States of America \\
LKA & Sri Lanka & VEN & Venezuela \\
MAR & Morocco & VNM & Vietnam \\
MEX & Mexico & & \\
\hline & & & \\
\hline
\end{tabular}


Table B.2: Goods/Sectors in GTAP-EG

\begin{tabular}{llll}
\hline AGR & Agricultural products & NFM & Non-ferrous metals \\
CNS & Construction & NMM & Non-metallic minerals \\
COL & Coal & OIL & Refined oil products \\
CRP & Chemical industry & OME & Other machinery \\
CRU & Crude oil & OMF & Other manufacturing \\
DWE & Dwellings & OMN & Mining \\
ELE & Electricity and heat & PPP & Paper-pulp-print \\
FPR & Food products & SER & Commercial and public services \\
GAS & Natural gas works & T_T & Trade margins \\
I_S & Iron and steel industry & TRN & Transport equipment \\
LUM & Wood and wood-products & TWL & Textiles-wearing apparel-leather \\
\hline
\end{tabular}

Table B.3: Mapping from GTAP-EG regions to model regions as of Table 1

\begin{tabular}{llc}
\hline Model Regions & \multicolumn{1}{c}{ GTAP-EG Regions } \\
\hline & & Annex $B$ \\
USA & United States & USA \\
EUR & OECD Europe (incl. EFTA) & DEU, DNK, EFT, FIN, GBR, REU, SWE \\
JPN & Japan & JPN \\
CAN & Canada & CAN \\
AUN & Australia, New Zealand & AUS, NZL \\
CEA & Central and Eastern Europe & CEA \\
FSU & Former Soviet Union & FSU \\
\hline & & Non-Annex B \\
CHN & China & CHN, HKG \\
IND & India & IND \\
ASI & Asia & KOR, LKA, MYS, PHL, RAS, SGP, THA, TWN, \\
& & VNM \\
MPC & Mexico and OPEC & IDN, MEX, RME, RNF, VEN \\
ROW & Rest of world & MAR, ROW, RSA, RSS, SAF, TUR \\
\hline
\end{tabular}


Table B.4: Mapping from GTAP-EG sectors to model sectors as of Table 1

\begin{tabular}{|c|c|c|}
\hline \multicolumn{2}{|c|}{ Model Sectors } & \multirow{2}{*}{$\begin{array}{l}\text { GTAP-EG Sectors } \\
\text { ergy }\end{array}$} \\
\hline \multicolumn{2}{|c|}{ Energy } & \\
\hline $\mathrm{COL}$ & Coal & $\mathrm{COL}$ \\
\hline $\mathrm{CRU}$ & Crude oil & CRU \\
\hline GAS & Natural gas & GAS \\
\hline OIL & Refined oil products & OIL \\
\hline ELE & Electricity & ELE \\
\hline \multicolumn{3}{|c|}{ Non-Energy } \\
\hline EIS & Energy-intensive sectors & CRP, I_S, NFM, NMM, PPP, TRN \\
\hline ROI & Rest of industry & $\begin{array}{l}\text { AGR, CNS, DWE, FPR, LUM, OME, OMF, OMN, } \\
\text { SER, T_T, TWL }\end{array}$ \\
\hline
\end{tabular}




\section{Appendix C: GHG Emission Reduction Targets for Annex-B countries}

\begin{tabular}{|c|c|c|c|}
\hline & Label $^{\mathrm{a}}$ & $\begin{array}{c}\text { Original Kyoto Targets }(O L D)^{\mathrm{b}} \\
\text { (\% of } 1990 \text { base year GHG emissions) }\end{array}$ & $\begin{array}{c}\text { Revised Targets }(N E W)^{\mathrm{c}} \\
(\% \text { of } 1990 \text { base year GHG emissions) }\end{array}$ \\
\hline Australia & AUN & 108 & 110.7 \\
\hline Austria & EUR & 87 & 92.9 \\
\hline Belgium & EUR & 92.5 & 93.8 \\
\hline Bulgaria & CEA & 92 & 95.2 \\
\hline Canada & CAN & 94 & 107.9 \\
\hline Croatia & CEA & 95 & 95 \\
\hline Czech Republic & CEA & 92 & 94.1 \\
\hline Denmark & EUR & 79 & 81.1 \\
\hline Estonia & FSU & 92 & 94.7 \\
\hline Finland & EUR & 100 & 107.8 \\
\hline France & EUR & 100 & 103.9 \\
\hline Germany & EUR & 79 & 80.7 \\
\hline Greece & EUR & 125 & 133.1 \\
\hline Hungary & CEA & 94 & 97.8 \\
\hline Iceland & EUR & 110 & 118 \\
\hline Ireland & EUR & 113 & 116.2 \\
\hline Italy & EUR & 93.5 & 95.3 \\
\hline Japan & JPN & 94 & 99.2 \\
\hline Latvia & FSU & 92 & 98 \\
\hline Liechtenstein & EUR & 92 & 107.9 \\
\hline Lithuania & EUR & 92 & 96.5 \\
\hline Luxemburg & EUR & 72 & 79.6 \\
\hline Monaco & EUR & 92 & 93 \\
\hline Netherlands & EUR & 94 & 95.2 \\
\hline New Zealand & AUN & 100 & 107 \\
\hline Norway & EUR & 101 & 105.3 \\
\hline Poland & CEA & 94 & 96.5 \\
\hline Portugal & EUR & 127 & 130.7 \\
\hline Romania & CEA & 92 & 96.2 \\
\hline Russian Federation & FSU & 100 & 105.7 \\
\hline Slovakia & CEA & 92 & 96.3 \\
\hline Slovenia & CEA & 92 & 100.4 \\
\hline Spain & EUR & 115 & 118.9 \\
\hline Sweden & EUR & 104 & 109.5 \\
\hline Switzerland & EUR & 92 & 96.6 \\
\hline Ukraine & FSU & 100 & 102.4 \\
\hline United Kingdom & EUR & 87.5 & 88.8 \\
\hline United States & USA & 93 & 96.8 \\
\hline
\end{tabular}

${ }^{\text {a }}$ Label of aggregate model region which includes the respective Annex B country

${ }^{\mathrm{b}}$ UNFCCC (1997)

${ }^{\mathrm{c}}$ Estimates by the European Commission accounting for sink credits based on UNFCCC (2001) 